\title{
Biorreactores de membranas cerámicas para tratamiento de aguas residuales urbanas
}

\author{
Patricia Ugarte ${ }^{1}$, Ana Ramo ${ }^{1}$, Mari Carmen Bordes ${ }^{2}$, Magda Lorente ${ }^{2}$, Elena Zuriaga ${ }^{3}$, \\ Enrique Sanchez ${ }^{2}$, Javier Rubert ${ }^{4}$, José Ángel Peña ${ }^{1}$, Miguel Menéndez ${ }^{1}$. \\ ${ }^{1}$ Grupo de Catálisis, Separaciones Moleculares e Ingeniería de Reactores (CREG) \\ Instituto de Investigación en Ingeniería de Aragón (I3A) \\ Universidad de Zaragoza, Mariano Esquillor s/n, 50018, Zaragoza, Spain. \\ Tel. +34-976762707, e-mail:pugarte@unizar.es \\ ${ }^{2}$ Instituto Universitario de Tecnología Cerámica (ITC) - Universitat Jaume I, Castellón. \\ ${ }^{3}$ Sociedad Fomento Agrícola Castellonense (FACSA), Castellón. \\ ${ }^{4}$ Naturcer, S.L., Onda (Castellón).
}

\begin{abstract}
Esta investigación se enmarca dentro del proyecto REBIABLE (RTC-2015-3485-5), cuyo objetivo es la puesta a punto e implementación de un reactor biológico de membranas cerámicas (C-MBR), competitivo para el tratamiento de aguas residuales urbanas, mediante la reducción de los costes iniciales asociados a las membranas. Se pretenden mejorar las propiedades antiensuciamiento de las membranas y estudiar distitntas variables de operación.
\end{abstract}

\section{Introducción}

El agua es un recurso imprescindible en nuestra vida diaria y en cada uno de los ecosistemas que forman el entorno. Por ello se debe preservar haciendo un uso sostenible y evitando su contaminación, ya que la calidad de ésta también es un parámetro importante. Una de las alternativas a los sistemas de depuración convencionales son los biorreactores de membrana (MBR) [1]. Los MBRs combinan el proceso biológico de fangos activos con el tratamiento por filtración mediante membranas, para separar los sólidos del fango activo del agua. El realizar la depuración y separación en la misma unidad de proceso hace que sean plantas de menor tamaño y además permite trabajar de forma flexible con diferentes volúmenes y cargas de trabajo [2]. Existen estudios recientes que demuestran que la tecnología MBR permite la eliminación de sustancias prioritarias, contaminantes emergentes y contaminación microbiológica, obteniéndose un agua con una calidad superior a la de los procesos convencionales [3].

\section{Experimental}

La planta consta de un reactor de lodos activados de 30 L. En la parte inferior del tanque hay un sistema de aireación. En estos reactores el suministro de aire tiene dos funciones: disminuir el ensuciamiento de la membrana y proporcionar oxígeno para el tratamiento biológico. Como se observa en la Figura 1, la instalación cuenta con 3 bombas peristálticas (alimentación, permeado y contralavado), un sensor de presión (para medir la presión transmembrana) y un control de nivel del tanque. En el interior del tanque se encuentra la membrana cerámica.

Las membranas se han extruido y sinterizado a escala de laboratorio (permeabilidad al agua: 2043 $\mathrm{L} \cdot \mathrm{h}^{-1} \cdot \mathrm{m}^{-2} \cdot \mathrm{bar}^{-1}$; diámetro medio de poro: $7 \mu \mathrm{m}$ y un área de $0.04 \mathrm{~m}^{2}$ ). A la hora de realizar los experimentos se ha operado con un proceso cíclico de filtrado (10 min permeado con $1 \mathrm{~min}$ de relajación y 1 min de contralavado por cada 30 $\min )$.

\section{Resultados}

Se muestra el efecto de la temperatura en dos experimentos. En ambos experimentos el caudal de permeado es de $12 \mathrm{~L} / \mathrm{m}^{2} \mathrm{~h}$. El reactor tiene una cantidad de sólidos suspendidos en el licor mezclado (MLSS) de 3-4 g/L. La planta se alimenta con un agua residual sintética preparada según la norma DIN 38412 L26, que contiene glucosa, extracto de carne, peptona, urea y sales. En ambos experimentos se ha medido la carga orgánica (DQO) de la alimentación y del agua filtrada a través de la membrana. Como se puede observar en la Tabla 1 , a temperaturas mayores el oxígeno disuelto es menor y hay una mayor eliminación de materia orgánica. Cuando las temperaturas del reactor son cercanas a los $27-28^{\circ} \mathrm{C}$, las bacterias tienen una actividad superior, es por esto que la DQO en el permeado es inferior y el porcentaje de eliminación (eficiencia), aumenta con respecto al otro experimento. Esto se debe a la buena actividad de los microorganismos a temperaturas cercanas a los 
27-28 ${ }^{\circ} \mathrm{C}$. La disminución de la cantidad de oxígeno disuelto se puede explicar por la actividad de las bacterias: al estar más activas consumen más oxígeno y el equilibrio entre la transferencia de oxígeno y el consumo se alcanza con un menor valor de concentración de oxígeno en agua. Otro parámetro que se ha medido es la presión transmembrana del experimento a lo largo del tiempo de operación. La presión aumenta de forma exponencial con el tiempo obteniéndose valores muy altos a corto plazo, lo que indica un ensuciamiento irreversible en la membrana cerámica.

\section{Conclusiones}

El efecto de la temperatura en el reactor es un factor clave para obtener un mayor porcentaje de eliminación de la materia orgánica. Hay que disminuir el ensuciamiento que se produce en la membrana para poder operar durante más tiempo sin llegar a valores altos de presión transmembrana.

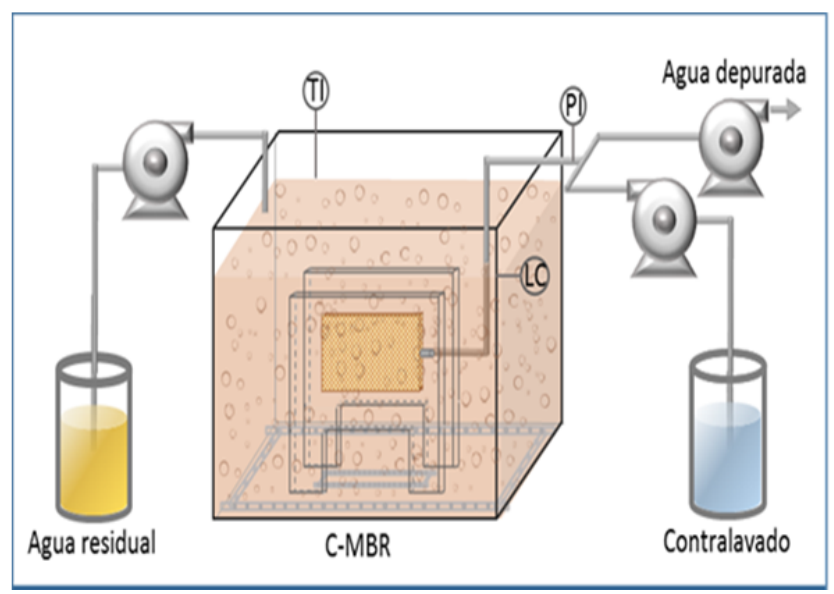

Figura 1. Esquema de la planta C-MBR.

\section{REFERENCIAS}

[1]. S. Judd, The MBR BOOK - Principes and Applications of Membrane Bioreactors for Waste and Wastewater treatment, PERGAMON P. 2006.

[2]. F. Coutte, D. Lecouturier, L. Firdaous, R. Kapel, L. Bazinet, C. Cabassud, and P. Dhulster, 10 - Recent Trends in Membrane Bioreactors. Elsevier B.V., 2017

[3]. P. Le-Clech, "Membrane bioreactors and their uses in wastewater treatments," Appl. Microbiol. Biotechnol., vol. 88, no. 6, pp. 1253-1260, 2010.

Tabla 1. Oxígeno disuelto, DQO del permeado, eficiencia, sólidos en suspensión (MLSS) y caudal del permeado para experimentos en el C-MBR a distintas temperaturas.

\begin{tabular}{ccccccc}
\hline & $\mathbf{T}\left({ }^{\circ} \mathbf{C}\right)$ & {$\left[\mathrm{O}_{2}\right]_{\text {dis }}(\mathbf{m g} / \mathbf{L})$} & $\begin{array}{c}\text { DQO permeado } \\
(\mathbf{m g} / \mathbf{L})\end{array}$ & Eficiencia (\%) & MLSS (g/L) & $\begin{array}{c}\mathbf{Q}_{\text {permeado }} \\
\left(\mathbf{L} / \mathbf{m}^{2} \mathbf{h}\right)\end{array}$ \\
\hline Exp 1 & $16-17$ & $3-4$ & $95-100$ & 78 & $3-4$ & 12 \\
Exp 2 & $27-28$ & $1,5-2$ & $25-35$ & 93 & $3-4$ & 12 \\
\hline
\end{tabular}

